\title{
Efficient and Facile One-Pot Synthesis of Novel Benzimidazoles using Rice Husk
}

By Suman, Rajvir Singh, Susheel Gulati \& Suprita Chaudhary Charan Singh Haryana Agricultural University

Abstract- New and facile one-pot approach for the synthesis of substituted benzimidazoles from the reaction of substituted benzaldehyde and o-phenylenediamine room temperature using Rice Husk Ash: $\mathrm{CaCl}_{2}\left(\mathrm{RHA}: \mathrm{CaCl}_{2}\right)$ as a green catalyst was presented in the paper. After the completion of the reaction, the reaction mixture was poured into ice-coldwater with stirring, and the precipitated product was filtered using the filter pump. The crude product was then recrystallized from ethanol to give analytically pure samples in good to excellent yield. The purity of compounds were characterized by melting point and thin-layer chromatography. The synthesized compounds were characterized by using ${ }^{1} \mathrm{HNMR}$ and FTIR spectral techniques. Metal-free, short reaction time, high yields, mild reaction condition, simple work-up, high atom economy, cost-effectiveness, and no need for column purification are some beauties of this methodology.

Keywords: rice husk, green catalyst, benzimidazole, metal-free, atom economy.

GJSFR-B Classification: FOR Code: 030299

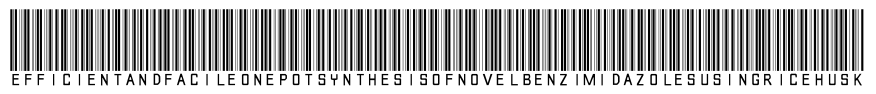

Strictly as per the compliance and regulations of:

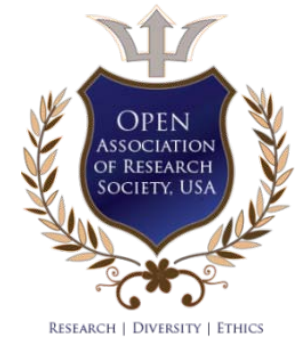

(c) 2020. Suman, Rajvir Singh, Susheel Gulati \& Suprita. This is a research/review paper, distributed under the terms of the Creative Commons Attribution-Noncommercial 3.0 Unported License http://creativecommons.org/licenses/by-nc/3.0/), permitting all non commercial use, distribution, and reproduction in any medium, provided the original work is properly cited. 


\title{
Efficient and Facile One-Pot Synthesis of Novel Benzimidazoles using Rice Husk
}

\author{
Suman $^{\alpha}$, Rajvir Singh ${ }^{\sigma}$, Susheel Gulati ${ }^{\circ} \&$ Suprita $^{\omega}$
}

\begin{abstract}
New and facile one-pot approach for the synthesis of substituted benzimidazoles from the reaction of substituted benzaldehyde and o-phenylenediamine room temperature using Rice Husk Ash: $\mathrm{CaCl}_{2}\left(\mathrm{RHA}: \mathrm{CaCl}_{2}\right)$ as a green catalyst was presented in the paper. After the completion of the reaction, the reaction mixture was poured into ice-coldwater with stirring, and the precipitated product was filtered using the filter pump. The crude product was then recrystallized from ethanol to give analytically pure samples in good to excellent yield. The purity of compounds were characterized by melting point and thin-layer chromatography. The synthesized compounds were characterized by using ${ }^{1} \mathrm{HNMR}$ and FTIR spectral techniques. Metal-free, short reaction time, high yields, mild reaction condition, simple work-up, high atom economy, cost-effectiveness, and no need for column purification are some beauties of this methodology.
\end{abstract}

Keywords: rice husk, green catalyst, benzimidazole, metal-free, atom economy.

\section{InTRODUCTION}

$\mathrm{n}$ recent years, the progress of science and technology gradually shifted more towards environmentally benign, sustainable, and green resources. In this series, much attention has been focused on the utilization of plant biomass as biocatalyst. Amongst the various biomasses, with abundant and renewable energy sources, rice husk is not only a potential source of energy but also a valueadded by-product[1].In the last days, there were many reasons associated with rice husk for not being effectively like (i) lack of awareness of its potential by farmers and industry persons, (ii) socio-economic problems, (iii) penetration of technology, (iv)lack of environmental concern and many others. The only solution to these problems associated with the utilization of this solid waste needs to be detected both in quality and quantity aspects. Benzimidazole and its derivatives have reported the number of biological importance like they can be used as anticonvulsant, antibacterial, antifungal, antitumor, anthelmintic, ant amoebic, analgesic, and antiulcer [2-3]. Recent results indicate that the benzimidazole structure can bind in the DNA minor groove and can act as a ligand to transition metals. So, it must be necessary to develop a mild and easy procedure for the synthesis of these bioactive chemicals. Generally, benzimidazoles were prepared by

Author $\alpha \sigma \rho \omega$ : Department of Chemistry, Chaudhary Charan Singh Haryana Agricultural University, Hisar, 125004, India.

e-mails: sgbhuna108@gmail.com,supritarana0006@gmail.com
CAN [4], microwave-assisted[5], lead peroxide [6].Despite of these methods, polycondensation of ophenylenediamine with aryl aldehydes is more efficient and facile. Recently, some of the green protocol for the synthesis of benzimidazole derivatives has been carried out, such as the use of pectin in water [7]. In continuation of these series, we want to explain the applicability of $\mathrm{RHA} \cdot \mathrm{CaCl}_{2}$ as a newly reported green catalyst which is reusable many times without loss of activity and performs the reaction under mild conditions with high yields.

\section{il. Experimental Details}

The contents of rice husk are hemicellulose $24.3 \%$, cellulose $34.4 \%$, lignin $19.2 \%$, ash $18.85 \%$ and the other substances are3.25\% [8]. Cellulose and lignin did not show the bonding properties because these are mostly inert but the monomeric components of hemicelluloses such as methyl glucuronic acid (monosaccharides), which become polar due to the electrometric effect of carboxylic acidic part. The active acidic monosaccharide can be extracted by removing lignin and cellulose from rice husk with an alkaline metal treatment [9]. All reagents and solvents were used in analytical grade and used without purification. Melting points were determined in open capillaries on a Ganson electric melting point apparatus and are uncorrected. Infrared spectra $\left(4000-350 \mathrm{~cm}^{-1}\right)$ of the synthesized compounds were recorded in $\mathrm{KBr}$ pellets on Perkin Elmer FT-IR-R2X spectrophotometer, and frequency was expressed in $\mathrm{cm}^{-1}$. The ${ }^{1} \mathrm{HNMR}$ spectrum was recorded in $\mathrm{CDCl}_{3}$ or $\mathrm{DMSO}-d_{6}$ using tetra methyl silanean internal reference on "Brucker Ac $400 \mathrm{~F}$ "(400 MHz) nuclear magnetic resonance spectrometer. The chemical shift values were quoted in delta (ppm).

\section{a) General procedure of the synthesis of biocatalyst}

The catalyst was prepared by sorption of anaqueous solution of $\mathrm{CaCl}_{2} \cdot 2 \mathrm{H}_{2} \mathrm{O}(7.35 \mathrm{gm}, 0.05$ $\mathrm{mmol}$ ) in per $\mathrm{mL}$ distilled water on rice husk (0.25 gm). The mixture was heated at $100{ }^{\circ} \mathrm{C}$ for 4 hours to give RHA.CaCl 2 [9].

b) General procedure of the synthesis of benzimidazole

O-phenylenediamine $(20 \mathrm{mmol})$ was added to a mixture of $\mathrm{RHA} \cdot \mathrm{CaCl}_{2}$ (20 mg), substituted aldehydes (20 mmol), and $10 \mathrm{~mL}$ distilled water . Thus the resulting mixture was stirred at room temperature for $40 \mathrm{~min}$. The progress of reaction was monitored by thin-layer 
chromatography (Ethyl acetate: n-hexane 2:8). After completion of the reaction, the mixture was workup by the addition of ice-coldwater. The yellow solid products was separated by simple filtration and recrystallized from ethanol. If the product was gummy, it was extracted with ethyl acetate, and the organic phase was washed with water and dried over sodium sulfate. The reaction was found to complete within 40 min to give 2$(1 \mathrm{H}$-benzimidazole-2yl) phenol 3(i) a product in quantitative yield (Table 3 , entry 1 ). Various derivatives of benzimidazole and their yield formed was shown in Table 2 under (Scheme-1). Also, the specialty of the catalyst in comparison of other is shown in Table 3.

Chemical reaction<smiles>Nc1ccccc1N</smiles>

1<smiles>[R]c1ccc([CH])c([R])c1[R]</smiles>

2(i)-2(ix)<smiles>[R]c1ccc(-c2nc3ccccc3[nH]2)c([R])c1[R]</smiles>

3 (i) -3 (ix)

Scheme-1

\section{ili. Result And Discussion}

The model reaction between salicylaldehyde 2(i) (2.44g; 20mmoles) and o-phenylene diamine(1) (3.74g; 20 mmoles) in the presence of $\mathrm{RHA} . \mathrm{CaCl}_{2}$ was taken in the flask and stirred for 40 min on the magnetic stirrer. The solid that separated and worked up with cold water and recrystallized from ethanol to furnish 3(i) as the product in quantitative yield (Table 3, Entry 1).Inspired by this result, the concentration of catalyst was optimized through the above reaction by using different amounts of catalyst i.e.0.12, 0.25, 0.50, 0.75, $1.00 \mathrm{gm}$ (Table 1, Entry 1-5) of RHA. $\mathrm{CaCl}_{2}$ in the water at room temperature for 40 min to give the desired products $3(i)$. The reaction procedure was performed in the absence of catalyst at the same condition; a low yield is obtained, which shows the value of the prescribed agitator. Fig.1a shows SEM images of untreated rice husk; this figure represents an irregular shape of fibers and rough surface; but a smooth and regular form was showed after treatment with hydrated calcium chloride $\left(\mathrm{CaCl}_{2} \cdot 2 \mathrm{H}_{2} \mathrm{O}\right)$. At low magnification, $\mathrm{RHA} \cdot \mathrm{CaCl}_{2}(\mathrm{Fig} 1 \mathrm{~b}$, C) shows a regular surface, but the shape of fiber particles does not appear accurately. But at high magnification RHA.CaCl ${ }_{2}$ (Fig. 1d)seems to be composed of regular-shapedp articles with a uniform distribution of $\mathrm{CaCl}_{2}$ on the surface. Due to this, calcium treatment improves the fiber surface and bond uniqueness by removing hemicelluloses and producing regular surface. This topography offers better fibermatrix interface bond and an increase in mechanical properties. Treatment by alkali and alkaline reduces the lignin and hemicellulose content in natural fibers, increases the surface area, allowing the dissemination of water molecules to the inner layers, and breaks the bonds between lignin-carbohydrate and hemicellulose [17].

\section{a) Catalyst recycles}

Reusability is one attractive advantage of green catalysts. A recycling experiment was conducted using the above-mentioned model reaction (Scheme 1). The syntheses were performed three times and the effect of recycling catalysts on yields of 3(i), as shown in Table 2 . In every cycle, the catalyst was almost quantitatively recovered, and after second and third-time use of catalyst, the decreasing yield is not much more significant.

b) Plausible Mechanism for Synthesis of Benzimidazole in the presence of $\mathrm{RHA}$. $\mathrm{CaCl}_{2}$

The possible mechanism for the synthesis of benzimidazole (Scheme 1) depicted below. The reaction proposed that the aryl aldehyde was first activated by green catalyst by nucleophilic attack on carbonyl group, then o-phenylene diamine attacks the activated carbonyl group of the compound, which leads to the formation of the intermediate and intermolecular cyclization proceeds to form the desired product. 


\section{RHA.CaCl${ }_{2}$}<smiles>Nc1ccccc1N</smiles><smiles>O=Cc1ccccc1</smiles><smiles>CNc1ccccc1NC</smiles><smiles>COC=Cc1ccccc1</smiles>

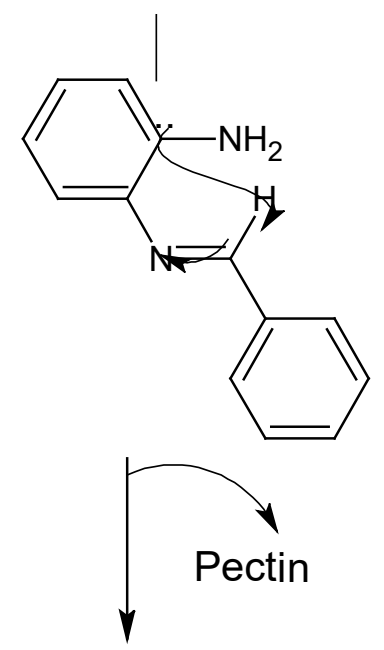
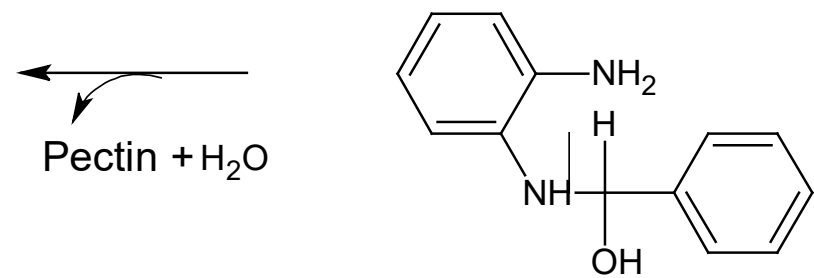<smiles>CC1(c2ccccc2)Nc2ccccc2N1</smiles>

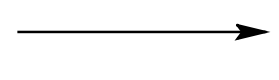

c) Spectral data of some selected compounds

i. 2-(1H-benzimidazol-2yl)phenol: pale yellow solid. mp: $293-296^{\circ} \mathrm{C} ;{ }^{1} \mathrm{H}$ NMR $\left(400 \mathrm{~Hz}, \mathrm{CDCl}_{3}\right): \delta 3.62$ (brd, $1 \mathrm{H}, \mathrm{OH}) ; 7.30-8.91(\mathrm{~m}, 8 \mathrm{H}, \mathrm{Ar}-\mathrm{H}) ; 10.38(\mathrm{~s}, 1 \mathrm{H}$, $\mathrm{NH}) ; \quad$ IR $(\mathrm{KBr}) \quad \mathrm{cm}^{-1} 3366 \quad(\mathrm{OH}), \quad 3165 \quad(\mathrm{~N}-\mathrm{H})$, 3035 $(\mathrm{C}=\mathrm{CH}), 1618(\mathrm{C}=\mathrm{C}$, aromatic $)$

ii. 2-(2-chlorophenyl)-1H-benzimidazole: pale yellow solid. mp: $225-226^{\circ} \mathrm{C}$; ${ }^{1} \mathrm{H}$ NMR $(400 \mathrm{~Hz}$, $\left.\mathrm{CDCl}_{3}\right): \delta 6.97-8.24(\mathrm{~m}, 8 \mathrm{H}, \mathrm{Ar}-\mathrm{H}), 11.01(\mathrm{~s}, 1 \mathrm{H}, \mathrm{NH}) ; \mathrm{IR}$

$(\mathrm{KBr}) \mathrm{cm}^{-1}: 3261(\mathrm{~N}-\mathrm{H}), 3030(\mathrm{C}=\mathrm{CH}), 1596(\mathrm{C}=\mathrm{C}$, aromatic), $754(\mathrm{C}-\mathrm{Cl})$

iii. 2-(3-nitrophenyl)-1H-benzimidazole: pale yellow solid. mp: $164-186^{\circ} \mathrm{C} ;{ }^{1} \mathrm{H}$ NMR $\left(400 \mathrm{~Hz}, \mathrm{CDCl}_{3}\right): \delta$ 6.12-8.28 (m, 8H, Ar-H), $10.33(\mathrm{~s}, 1 \mathrm{H}, \mathrm{NH})$; IR $(\mathrm{KBr})$ $\mathrm{cm}^{-1}: 3326(\mathrm{~N}-\mathrm{H}), 2968(\mathrm{C}=\mathrm{CH}), 1590(\mathrm{C}=\mathrm{C}$, aromatic), $1318\left(\mathrm{NO}_{2}\right)$ 
d) Comparison of the results of the present methods for the synthesis of benzimidazoles with the reported methods

Table 4 indicates the comparison of the activity of different catalysts by considering the yield of the reaction. We observed that the $\mathrm{RHA} \cdot \mathrm{CaCl}_{2}$ gives catalytic activity in terms of product yield, solvent, and response time of reaction compared to other catalysts in the literature such as $\mathrm{CAN}, \mathrm{p}-\mathrm{TsOH}$, Metal-Nitrate, Ammonium Chloride, Ring-Closing. RHA. $\mathrm{CaCl}_{2}$ is a readily available and inexpensive biocatalyst, which makes this method green and mild. Also the above catalyst is a renewable catalyst that follows one of the green chemistry principles regarding the maximum yield of renewable resources.

\section{Conclusion}

In summary, we have developed an efficient catalytic system for the synthesis of substituted benzimidazoles by using rice husk. Under the improved method, it offers several benefits over the previous methods, which includes the elimination of toxic chemicals, cheap, and the main product was obtained in good to excellent yields. Furthermore, the rice husk catalytic system could be reuse up to three times without significant loss of activity. All synthesized compounds were obtained by precipitation without the need for column purification. This current improved method is capable of minimizing the use of hazardous chemicals and, at the same time, provides an alternative way of bio-waste management. We predict that the current procedure will provide a great utility in the synthesis of other heterocyclic compounds shortly.

\section{ACKNOWLEDGMENT}

We are very thankful to Chaudhary Charan Singh HAU Hisar for providing necessary research facilities and also Sophisticated Analytical Instrumentation Facility, PU Chandigarh for NMR, IR, and SEM analysis.

\section{References Références Referencias}

1. Vlaev, L.T., Markovska, I.G. and Lyubchev, L.A., 2003. Non-isothermal kinetics of pyrolysis of rice husk. ThermochimicaActa, 406(1-2), pp.1-7.

2. Kalyankar, T.M., Pekamwar, S.S., Wadher, S.J., Tiprale, P.S. and Shinde, G.H., 2012. Review on benzimidazole derivative. International Journal of Chemical and Pharmaceutical Sciences, 3(4), pp.18.

3. Khalafi-Nezhad, A., Rad, M.S., Mohabatkar, H., Asrari, Z. and Hemmateenejad, B., 2005. Design, synthesis, antibacterial and QSAR studies of benzimidazole and imidazole chloroaryloxyalkyl derivatives. Bioorganic \& medicinal chemistry, 13(6), pp.1931-1938.
4. Kidwai, M., Jahan, A. and Bhatnagar, D., 2010. Polyethylene glycol: A recyclable solvent system for the synthesis of benzimidazole derivatives using CAN as catalyst. Journal of chemical sciences, 122(4), pp.607-612.

5. Lopez, S.E., Restrepo, J., Perez, B., Ortiz, S. and Salazar, J., 2009. One-Pot Microwave Promoted Synthesis of 2-Aryl-1H-benzimidazoles Using Sodium Hydrogen Sulfite. Chemlnform, 40(50), p.i.

6. Patil, V.D., Patil, J., Rege, P. and Dere, G., 2010. Mild and efficient synthesis of benzimidazole using lead peroxide under solvent-free conditions. Synthetic Communications ${ }^{\circledR}, 41(1)$, pp.58-62.

7. Akansha, A., Deepali, A., Anamika, B. and Kumar, K.V., A Mild and Environmentally benign Synthesis of Benzimidazoles: Relevance to the pectin hetero Polysaccharide as a Catalyst. Research Journal of Recent Sciences ISSN, 2277, p.2502.

8. Joseph, K., TolêdoFilho, R.D., James, B., Thomas, S. and Carvalho, L.H.D., 1999. A review on sisal fiber reinforced polymer composites. RevistaBrasileira de EngenhariaAgrícola e Ambiental, 3(3), pp.367-379.

9. Patel, M., Karera, A. and Prasanna, P., 1987. Effect of thermal and chemical treatments on carbon and silica contents in rice husk. Journal of Materials Science, 22(7), pp.2457-2464.

10. Eshghi, H., Rahimizadeh, M., Shiri, A. and Sedaghat, P., 2012. One-pot synthesis of benzimidazoles and benzothiazoles in the presence of $\mathrm{Fe}$ (HSO4) 3 as a new and efficient oxidant. Bull. Korean Chem. Soc, 33(2), pp.515-518.

11. Gogoi, P. and Konwar, D., 2006. An efficient and one-pot synthesis of imidazolines and benzimidazoles via anaerobic oxidation of carbonnitrogen bonds in water. Tetrahedron letters, 47(1), pp.79-82.

12. Xiangming,, H., Huiquinag, M. and Yulu, W. 2007. P$\mathrm{TsOH}$ catalyzed synthesis of 2-arylsubstituted benzimidazoles. ARKIVOK(Archive for Organic Chemistry), 13, pp.150-154.

13. Mobinikhaledi, A., FOROUGHIFAR, N. and Kalhor, M., 2010. An efficient synthesis of Schiff bases containing benzimidazole moiety catalyzed by transition metal nitrates. Turkish Journal of Chemistry, 34(3), pp.367-374.

14. Kathirvelan, D., Yuvraj, P., Babu, K., Nagarajan, A. S. and Reddy, B. S. R. (2013). A green synthesis of benzimidazoles. Indian Journal of Chemistry, 52B(08), 1152-1156.

15. Vaidehi, B. N. B. and Deepika, K. G. 2012. Synthesis and Biological evaluation of 2-substituted benzimidazoles. International Journal of Pharma and Bio Science, 3(3), pp. 2631. 
Graphical Abstract:

Figures
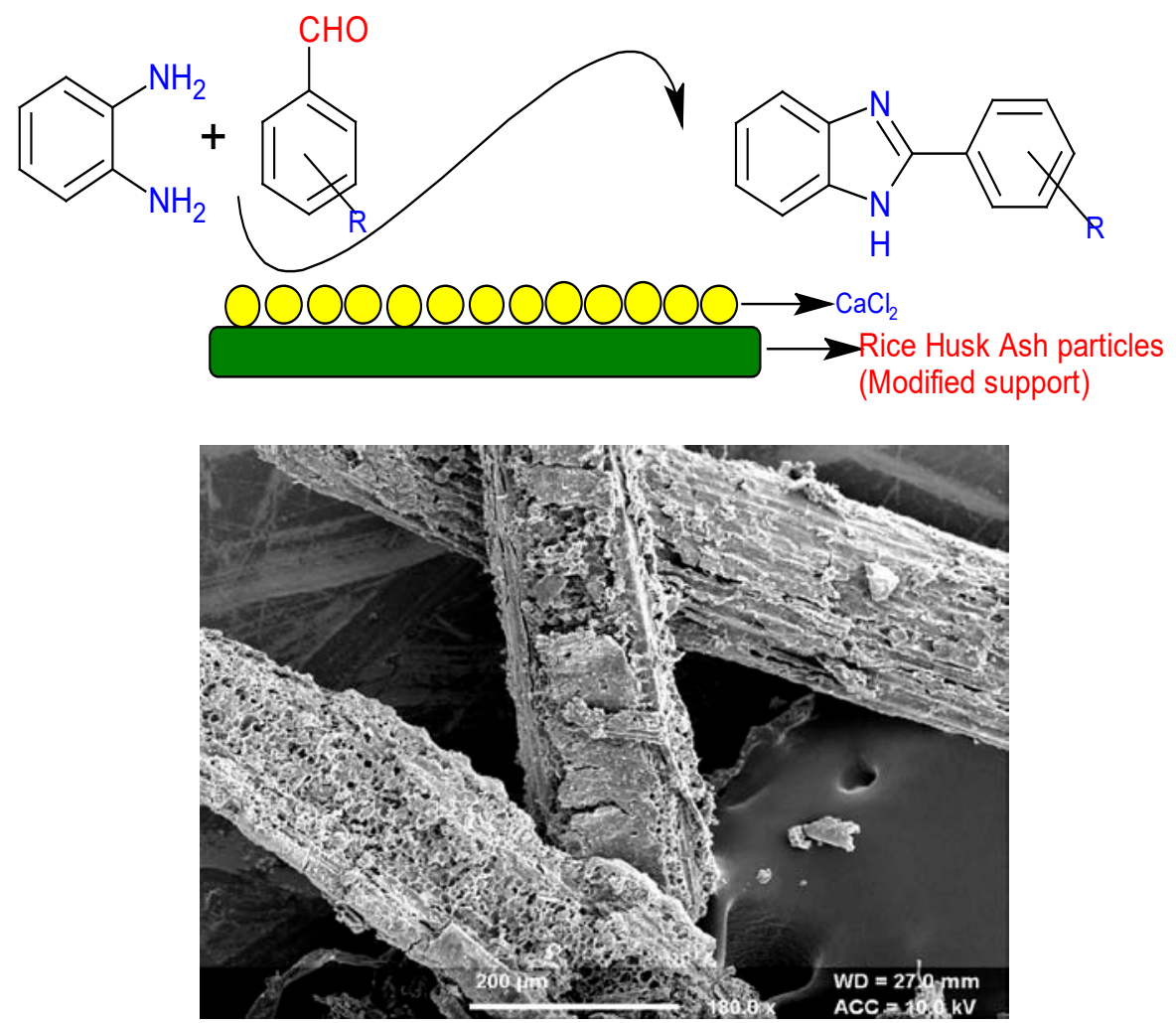

Fig.: 1a SEM Images of untreated Rice Husk
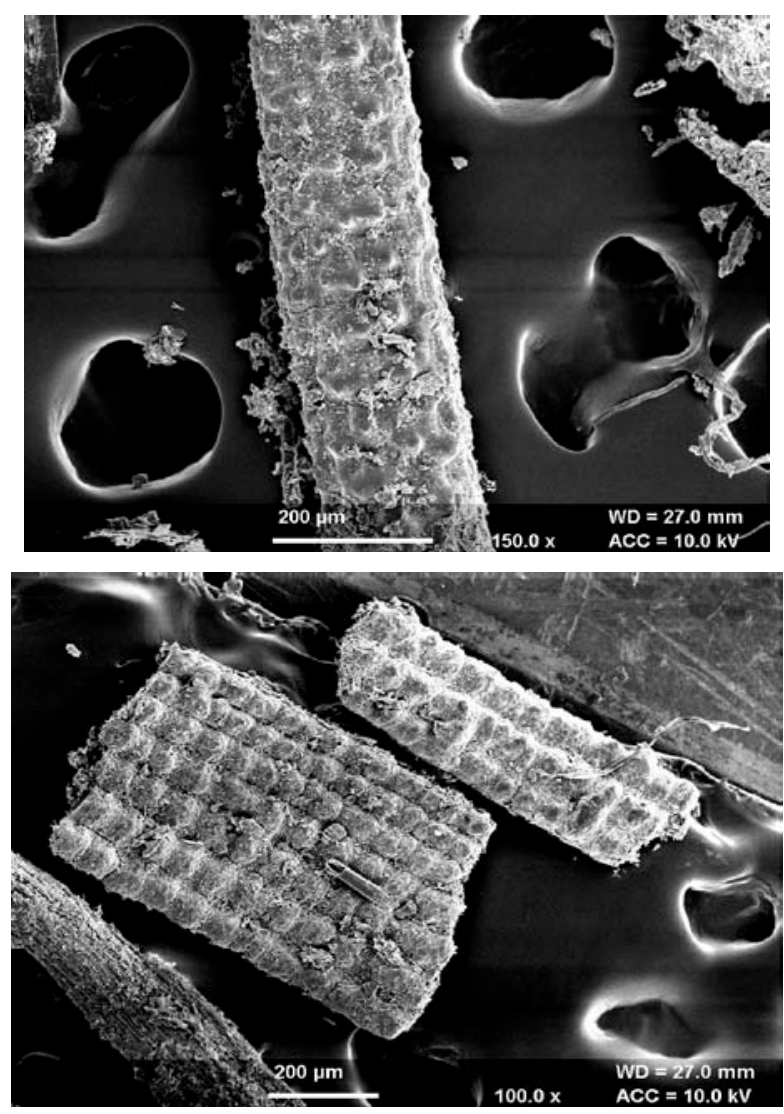

Fig.: 1b, c SEM of $\mathrm{RH} . \mathrm{CaCl}_{2}$ at low magnification 


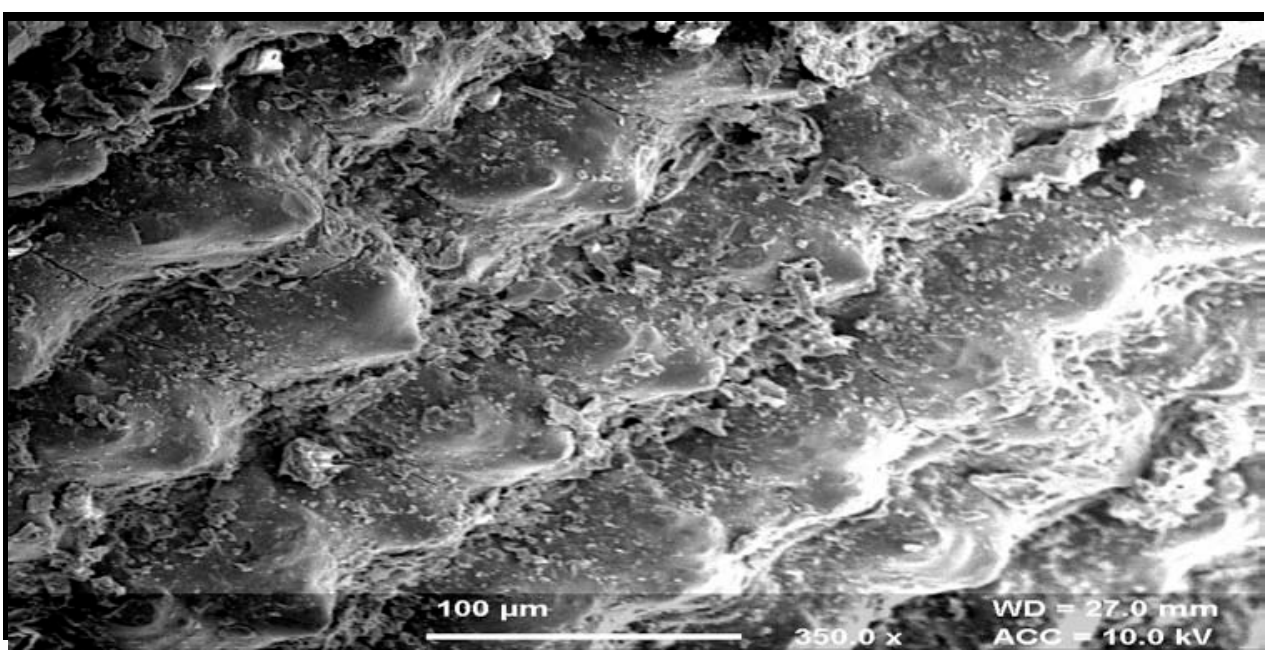

Fig.: 1d SEM of RHA.CaCl 2 at high magnification

Tables

Table 1: Screening of RHA.CaCl${ }_{2}$ for the synthesis of 3(i)

\begin{tabular}{|c|c|c|c|}
\hline Entry & $\begin{array}{c}\text { Amount of Catalyst } \\
(\mathbf{g m})\end{array}$ & Time (min) & Yield \\
\hline 1. & 0.12 & 75 & 79 \\
\hline 2 & 0.25 & 40 & 82 \\
\hline 3 & 0.50 & 30 & 80 \\
\hline 4 & 0.75 & 25 & 76 \\
\hline 5 & 1.00 & 25 & 76 \\
\hline
\end{tabular}

Entry 2 is the best concentration for the prescribed catalyst

Table 2: Reusability of catalyst

\begin{tabular}{|c|c|c|c|c|}
\hline Reuse Cycle & Fresh & First & Second & Third \\
\hline Time (min) & 40 & 40 & 60 & 90 \\
\hline Yield (\%) & 82 & 82 & 78 & 76 \\
\hline
\end{tabular}

Table 3: Synthesis of benzimidazoles in presence of $\mathrm{RHA} \cdot \mathrm{CaCl}_{2}$

\begin{tabular}{|c|c|c|c|c|c|c|c|}
\hline Entry & $\mathbf{R}$ & $\mathbf{R}^{1}$ & $\mathbf{R}^{2}$ & Product & Yield & Phase & MPt. $\left({ }^{\circ} \mathrm{C}\right)[\mathrm{Ref}]$ \\
\hline 1 & $\mathrm{OH}$ & $\mathrm{H}$ & $\mathrm{H}$ & $3(\mathrm{i})$ & 82 & Solid & $180-182[10]$ \\
\hline 2 & $\mathrm{H}$ & $\mathrm{OH}$ & $\mathrm{H}$ & 3 (ii) & 92 & Solid & $282-284[11]$ \\
\hline 3 & $\mathrm{Cl}$ & $\mathrm{H}$ & $\mathrm{H}$ & 3 (iii) & 88 & Solid & $225-226[10]$ \\
\hline 4 & $\mathrm{CH}_{3}$ & $\mathrm{CH}_{3}$ & $\mathrm{H}$ & $3(\mathrm{iv})$ & 86 & Gummy & --------- \\
\hline 5 & $\mathrm{H}$ & $\mathrm{OH}$ & $\mathrm{OH}$ & $3(\mathrm{v})$ & 90 & Gummy & ------- \\
\hline 6 & $\mathrm{H}$ & $\mathrm{NO}_{2}$ & $\mathrm{H}$ & $3(\mathrm{vi})$ & 84 & Solid & $164-186[10]$ \\
\hline 7 & $\mathrm{H}$ & $\mathrm{H}$ & $\mathrm{OCH}_{3}$ & $3(\mathrm{vii})$ & 90 & Solid & $223-225[10]$ \\
\hline 8 & $\mathrm{H}$ & $\mathrm{H}$ & $\mathrm{OH}$ & $3(\mathrm{viii})$ & 82 & Solid & $285-287[11]$ \\
\hline 9 & $\mathrm{H}$ & $\mathrm{H}$ & $\mathrm{Cl}$ & $3(\mathrm{ix})$ & 78 & Solid & $294-296[10]$ \\
\hline
\end{tabular}

Table 4: Comparison of the results with the reported methods

\begin{tabular}{|c|c|c|c|c|c|c|}
\hline S. No. & Catalyst & Solvent & Temperature $\left({ }^{\circ} \mathrm{C}\right)$ & Time $(\mathrm{min})$ & Yield (\%) & Literature \\
\hline 1 & CAN & PEG & 50 & 120 & 90 & {$[4]$} \\
\hline 2 & p-TsOH & DMF & 80 & 10 & 82 & {$[12]$} \\
\hline 3 & Metal-Nitrate & Methanol & RT & 30 & 80 & {$[13]$} \\
\hline 4 & Ammonuim Chloride & Ethanol & $80-90$ & 120 & 78 & {$[14]$} \\
\hline 5 & Ring-Closing & Ethanol & 90 & 120 & 78 & {$[15]$} \\
\hline 7 & RHA.CaCl & Water & RT & 40 & 82 & Present work \\
\hline
\end{tabular}

